\title{
Sensorless Induction Motor Drive Based on Model Reference Adaptive System Scheme Utilising a Fictitious Resistance
}

Research Article Soufien Hajji1 ${ }^{1}$ Ramzi Ben Chehida², Hichem Zayani1,3, Noomen Bouaziz ${ }^{3}$, Youssef Agrebi Zorgani1 ${ }^{1,3, *}$

${ }^{1}$ Laboratory of Sciences and Techniques of Automatic control \& computer engineering (Lab-STA), National School of Engineering of Sfax, University of Sfax. Postal Box 1173, 3038 Sfax, Tunisia

2 Institut Supérieur des Etudes Technologiques de Bizerte, Route Menzel Abderrahmen - Zarzouna 7021 Bizerte, 7021, Tunisia

${ }^{3}$ Institut Supérieur des Etudes Technologiques de Sfax, Route de mahdia Km 2.5, 3099 El Bustan, Sfax, Tunisia

Received: August 18, 2020; Accepted: November 08, 2020

\begin{abstract}
This article presents a new development of an indirect stator flux-oriented controller for sensorless speed induction motor drive utilising instantaneous and steady-state values, respectively, of a fictitious resistance symbolised as $R_{-} \mathrm{f}$. The dimension of the fictitious quantity, in this context, is the ohm, which is the difference between the stator $d$ - and $q$-axis fictitious resistances. However, from the measurement of the stator voltage and currents of the machine, two independent resistance estimators are built. Therefore, the first is considered as a reference model of the induction machine (IM), and the second is considered as an adjustable model. Subsequently, the error between the states of the two models is used to drive a suitable adaptation mechanism that generates the estimation of the speed, for the adjustable model. Furthermore, the structure of the proposed estimator is free from stator resistance and eliminates the requirement of any flux computation. All the detailed simulation study is carried out in MATLAB/Simulink to validate the proposed method and to highlight the robustness and the stability of the proposed model reference adaptive system estimator.
\end{abstract}

Keywords: indirect stator flux-oriented controller (ISFOC) model • model reference adaptive system (MRAS) • fictitious resistance • rotor speed estimation • induction motor (IM)

\section{Introduction}

The induction motor (IM) has been used mainly at a constant speed for a long period; however, its control remains a challenge for researchers to optimise and control the machine in variable speed drives. With advances in power electronics such as the appearance of thyristors and later, IGBT transistors and digital electronics such as the development of the new digital signal processor (DSP), the problem of variable speed drive is solved and control strategies have been implemented in satisfactory conditions.

The asynchronous machine can be controlled according to three types of control, such as scalar control, direct torque control (DTC) and field-oriented control. The last control strategy FOC presents a good accuracy for torque and speed. Therefore, it is considered to be the best solution for variable speed industrial applications, which is accomplished in one of two ways. The first is called the direct control method, which requires the acknowledgement of the flux module and phase at any time. However, the flux measurement can be carried out by a flux sensor, which increases the manufacturing cost, or by flux estimation from the voltage, the current and the speed measurements. The second is named the indirect control method, which consists of using directly the flux reference amplitude; consequently, the vector control will be simplified.

To achieve speed control, it is necessary to place a mechanical sensor on the shaft of the machine. This solution requires additional space on the machine shaft, which reduces the reliability of the actuator in the hostile environment and increases the actuator production cost; as a result, the need arises for a software sensor. To broach this problem, sensorless speed control is necessary to estimate the value and the rotor speed trajectory. 
The design of such sensors is mainly based on observer synthesis or adaptive methods allowing the parametric identification and sensorless control of the IM. Nowadays, developed research works are focused on the IM drive, which uses a high-performance sensorless vector control strategy. In the literature, several sensorless control methods have appeared such as speed adaptive flux Leunberger observers (Jouili et al., 2015; Popovic et al., 2014), predictive control methods (Alkorta et al., 2014; Wang, 2014), high-frequency signal injection (Gao et al., 2013; Matic et al., 2015; Yoon and Sul, 2014), extended Kalman filters (Alonge et al., 2015; Habibullah and Lu, 2015; Rayyam and Zazi, 2019), artificial neural networks (ANNs) (Niasar and Khoei, 2015; Verma et al., 2014), sliding-mode observers (Comanescu et al., 2015; Gennaro et al., 2014; Mezouar et al., 2008), adaptive observer design (Farza et al., 2018), high gain observer (Farza et al., 2011) and model reference adaptive system (MRAS).

The majority of speed estimation techniques require an important calculation time because their models are more or less complex, while the reference model method has great flexibility when it is implemented on a real process.

The sensorless speed based on the MRAS method can be divided into four groups:

- The classical MRAS technique; this method consists to develop two models, one as a reference and the other as an adjustable, which are used to estimate the rotor (or stator) flux from the knowledge of currents and voltages stator. Getting the estimated speed is assured by cancelling the difference between the rotor (or stator) flux of the reference model and the adjustable one, while using the theory of hyper stability to obtain the adaptive mechanism (Agrebi Zorgani et al., 2010, 2012, 2016, 2018).

- Estimation of the speed using the MRAS method and based on the estimation of the electromotive force. The difference between the reference and the adjustable EMF model will be applied to the adaptation mechanism to converge the estimated speed to its real value (Maiti and Chakraborty, 2010; Rashed and Stronache, 2004; Urbanski, 2014).

- The MRAS method using the stator currents estimation. The reference model (measured stator current) and the adjustable model (estimated stator current) will be compared to obtain the signal of the speed's error correction (Dybkowski, 2018; Dybkowski and Orlowska-Kowalska, 2013; Orlowska and Dubowski, 2010; Thuy Pham et al., 2018).

In this context, this article examines the MRAS approach to estimate the rotor speed from the measurement of current and voltage stator. This new model reference adaptive for vector-controlled squirrel cage IM is based on fictitious resistance symbolised as $R_{-}$f. In the beginning, an indirect stator flux-oriented controller (ISFOC) scheme is presented for an IM drive. Then, a detailed mathematical analysis of the suggested approach is presented. Afterwards, the stability of the MRAS estimators is examined. In the end, to demonstrate the effectiveness and robustness of the R-MRAS scheme, simulation results are given. In the literature, Abhisek and Sukanta (2016) propose a new fictitious $d$-and $q$-axis resistance error based MRAS (R-MRAS) for the estimation of speed for IM drive. However, the authors present a direct field-oriented control (DFOC) for a three-phase IM that generates direct and quadrature reference voltages $\mathrm{Vd}$ and $\mathrm{Vq}$. These values have to be used to drive the space vector pulse with modulation (SVPWM) inverter.

The first main contribution of this article is to formulate a detailed mathematical equation for a new speed sensorless ISFOC IM drives based on the MRAS state estimator utilising a fictitious resistance. This resistance is obtained as the difference between the $d$ - and $q$-axis stator resistances in static reference denoted as Rf. However, the envisaged expression does not include the term of the stator resistance. Moreover, the proposed strategy does not need any sort of flux computation, and thus makes the scheme insensitive to the problem's integration of the back electromotive force of the machine, enabling low-speed estimation quite accurate. The second main contribution of this article is to validate the effectiveness and the robustness of the proposed technique by simulation. Therefore, a stability test as well as tests for different speeds are presented.

This article is structured in four sections. In Section 2, the mathematical equations of the proposed MRAS scheme utilising a fictitious resistance R-MRAS are described. Furthermore, the system stability analysis through first-order eigenvalues perturbation along with overall system stability analysis in the speed-torque domain is detailed. Section 3 presents the simulation results for various operating conditions and speed patterns. Finally, the conclusion is given in Section 5 . 


\section{Mathematical Equations of Proposed R-MRAS}

\subsection{MRAS technique}

Two models are being explained by the MRAS strategy. The first one is called the reference model. It does not include the parameter to be estimated. The second one is called the adjustable model, that involves the quantity to be estimated. Afterwards, a suitable adaptive mechanism will be driven by the error between the outputs of the adjustable model and reference one (Figure 1). The adaptive mechanism should be designed to assure the stability of the control system.

\subsection{Reference and adjustable models}

In the synchronously rotating frame, the stator voltages of IM are given expressions (1) and (2):

$$
\begin{aligned}
& \mathrm{v}_{\mathrm{ds}}=\mathrm{R}_{\mathrm{s}} \mathrm{i}_{\mathrm{ds}}+\frac{\mathrm{M}}{\mathrm{L}_{\mathrm{r}}} \frac{\mathrm{d} \phi_{\mathrm{dr}}}{\mathrm{dt}}+\sigma \mathrm{L}_{\mathrm{s}} \frac{\mathrm{di} \mathrm{ds}_{\mathrm{ds}}}{\mathrm{dt}}-\omega_{\mathrm{s}} \frac{\mathrm{M}}{\mathrm{L}_{\mathrm{r}}} \phi_{\mathrm{qr}}-\omega_{\mathrm{s}} \sigma \mathrm{L}_{\mathrm{s}} \mathrm{i}_{\mathrm{qs}} \\
& \mathrm{v}_{\mathrm{qs}}=\mathrm{R}_{\mathrm{s}} \mathrm{i}_{\mathrm{qs}}+\frac{\mathrm{M}}{\mathrm{L}_{\mathrm{r}}} \frac{\mathrm{d} \phi_{\mathrm{qr}}}{\mathrm{dt}}+\sigma \mathrm{L}_{\mathrm{s}} \frac{\mathrm{di}_{\mathrm{qs}}}{\mathrm{dt}}+\omega_{\mathrm{s}} \frac{\mathrm{M}}{\mathrm{L}_{\mathrm{r}}} \phi_{\mathrm{dr}}+\omega_{\mathrm{s}} \sigma \mathrm{L}_{\mathrm{s}} \mathrm{i}_{\mathrm{ds}}
\end{aligned}
$$

where

$$
\begin{aligned}
& \phi_{\mathrm{dr}}=\frac{\mathrm{L}_{\mathrm{r}} \phi_{\mathrm{ds}}-\left(\mathrm{L}_{\mathrm{s}} \mathrm{L}_{\mathrm{r}}-\mathrm{M}^{2}\right) \mathrm{i}_{\mathrm{ds}}}{\mathrm{M}} \\
& \phi_{\mathrm{qr}}=\frac{\mathrm{L}_{\mathrm{r}} \phi_{\mathrm{qs}}-\left(\mathrm{L}_{\mathrm{s}} \mathrm{L}_{\mathrm{r}}-\mathrm{M}^{2}\right) \mathrm{i}_{\mathrm{qs}}}{\mathrm{M}}
\end{aligned}
$$

Replace the expressions of $\phi_{\mathrm{dr}}$ and $\phi_{\mathrm{qr}}$ in Eqs (1) and (2), then:

$$
\mathrm{v}_{\mathrm{ds}}=\mathrm{R}_{\mathrm{s}} \mathrm{i}_{\mathrm{ds}}+\frac{\mathrm{d} \phi_{\mathrm{ds}}}{\mathrm{dt}}-\omega_{\mathrm{s}} \phi_{\mathrm{qs}}
$$

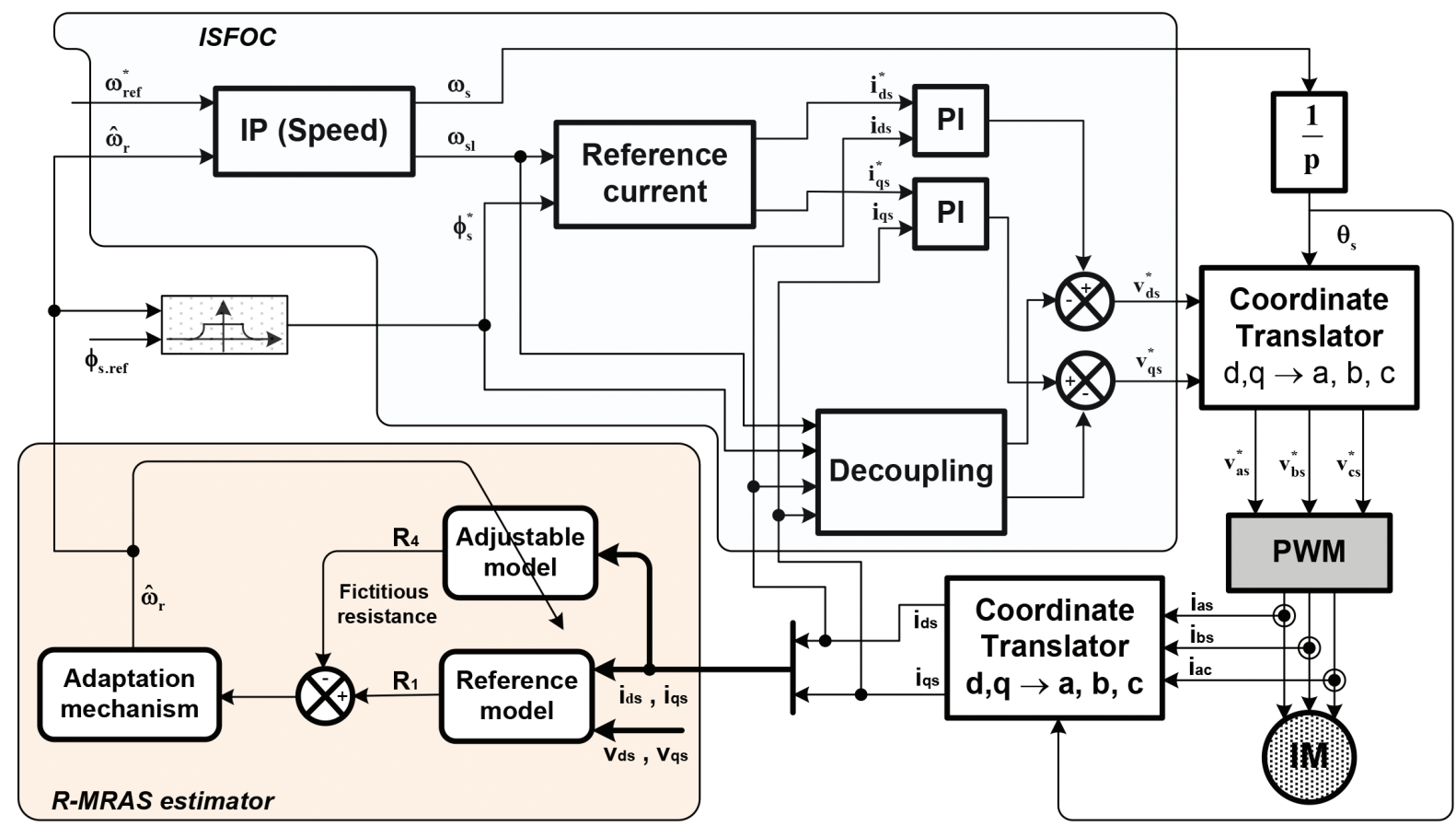

Fig. 1. Synoptic of the model reference adaptive system with ISFOC strategy. 


$$
\mathrm{v}_{\mathrm{qs}}=\mathrm{R}_{\mathrm{s}} \mathrm{i}_{\mathrm{qs}}+\frac{\mathrm{d} \phi_{\mathrm{qs}}}{\mathrm{dt}}+\omega_{\mathrm{s}} \phi_{\mathrm{ds}}
$$

Now dividing the $d$-axis stator voltage components $v_{\mathrm{ds}}$ by $i_{\mathrm{ds}}$ and $q$-axis stator voltage components $v_{\mathrm{qs}}$ by ids, then:

$$
\mathrm{R}_{1}=\frac{\mathrm{v}_{\mathrm{ds}}}{\mathrm{i}_{\mathrm{ds}}}-\frac{\mathrm{v}_{\mathrm{qs}}}{\mathrm{i}_{\mathrm{qs}}}
$$

Since the dimension of $R_{1}$ represents a resistance which is specified as fictitious resistance. Furthermore, expression (7) does not include the expression $\omega_{\mathrm{r}}$, then is considered as the reference model for the R-MRAS.

Substituting values of $v_{\mathrm{ds}}$ and $v_{\mathrm{qs}}$ from Eqs (5) and (6) in Eq. (7), the novel R-MRAS expression will be:

$$
\mathrm{R}_{2}=\left(\frac{\mathrm{d} \phi_{\mathrm{ds}}}{\mathrm{dt}} \cdot \frac{1}{\mathrm{i}_{\mathrm{ds}}}-\frac{\mathrm{d} \phi_{\mathrm{qs}}}{\mathrm{dt}} \cdot \frac{1}{\mathrm{i}_{\mathrm{qs}}}\right)-\omega_{\mathrm{s}}\left(\frac{\phi_{\mathrm{ds}}}{\mathrm{i}_{\mathrm{qs}}}+\frac{\phi_{\mathrm{qs}}}{\mathrm{i}_{\mathrm{ds}}}\right)
$$

For ISFOC, the flux is constant $\phi_{\mathrm{ds}}=\phi \mathrm{s}$ and $\phi_{\mathrm{qs}}=0$. Moreover, during a steady-state, the derived terms disappear. Therefore, expression (8) can be written as:

$$
\begin{aligned}
& \mathrm{R}_{3}=-\omega_{\mathrm{s}} \frac{\phi_{\mathrm{s}}}{\mathrm{i}_{\mathrm{qs}}} \\
& \text { or } \omega_{\mathrm{s}}=\omega_{\mathrm{r}}+\omega_{\mathrm{sl}}
\end{aligned}
$$

and under stator flux orientation $\omega_{\mathrm{sl}}=\frac{\mathrm{L}_{\mathrm{s}} \mathrm{R}_{\mathrm{r}}}{\mathrm{L}_{\mathrm{r}}} \frac{1}{\left(\phi_{\mathrm{s}}-\sigma \mathrm{L}_{\mathrm{s}} \mathrm{i}_{\mathrm{ds}}\right)} \mathrm{i}_{\mathrm{qs}}$

$$
\begin{gathered}
\mathrm{R}_{4}=-\left(\frac{\mathrm{L}_{\mathrm{s}} \mathrm{R}_{\mathrm{r}}}{\mathrm{L}_{\mathrm{r}}} \frac{1}{\left(\phi_{\mathrm{s}}-\sigma \mathrm{L}_{\mathrm{s}} \mathrm{i}_{\mathrm{ds}}\right)} \mathrm{i}_{\mathrm{qs}}+\omega_{\mathrm{r}}\right) \frac{\phi_{\mathrm{s}}}{\mathrm{i}_{\mathrm{qs}}} \text { then: } \\
\mathrm{R}_{4}=-\frac{\mathrm{L}_{\mathrm{s}} \mathrm{R}_{\mathrm{r}}}{\mathrm{L}_{\mathrm{r}}} \frac{\phi_{\mathrm{s}}}{\left(\phi_{\mathrm{s}}-\sigma \mathrm{L}_{\mathrm{s}} \mathrm{i}_{\mathrm{ds}}\right)}-\omega_{\mathrm{r}} \frac{\phi_{\mathrm{s}}}{\mathrm{i}_{\mathrm{qs}}}
\end{gathered}
$$

In the expression of $R_{4}$, we find the rotor speed of IM; as a consequence, it can be considered as the adjustable model of R-MRAS. Figure 2 shows the synoptic of the speed estimation strategy by a fictitious resistance, which is based on model reference adaptive.

It is interesting to add a small value $(\rho=0.00001)$ to the $i_{\text {qs }}$ current components in the denominator to ensure the satisfactory working of the algorithm, under a no-load condition.

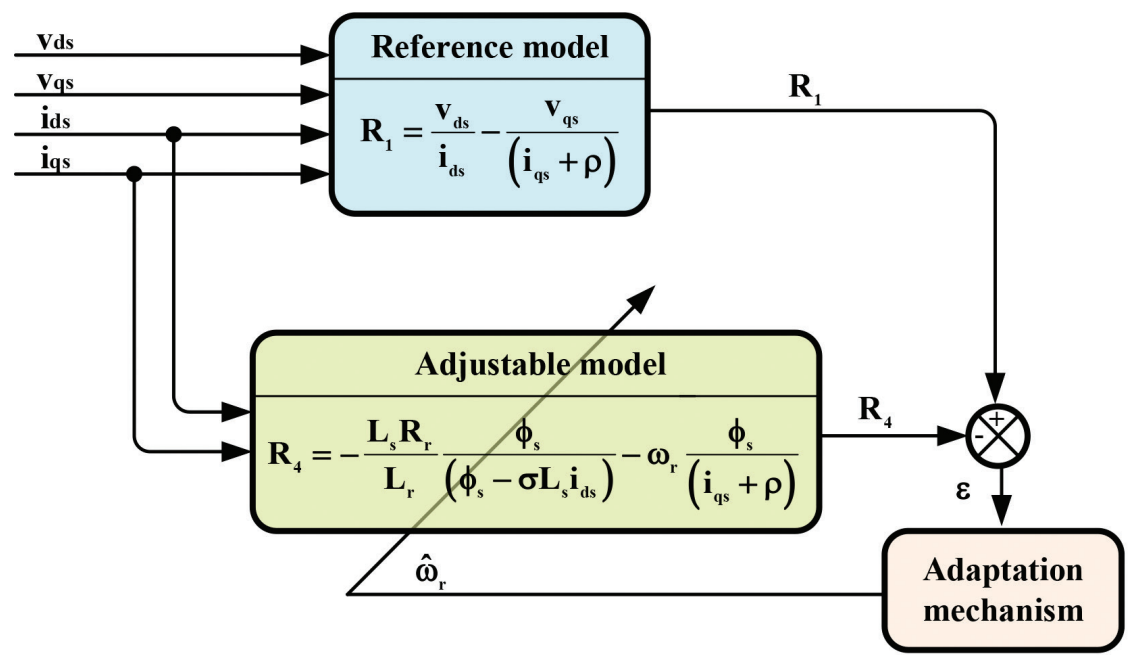

Fig. 2. Synoptic of the speed estimation strategy by a fictitious resistance based on model reference adaptive. 


\subsection{Adaptation mechanism}

According to the synchronous rotating form, the state space equation of IM is presented as:

where $\left\{\begin{array}{l}\frac{d x}{d t}=A x+B u \\ y=C x\end{array}\right.$

$$
\begin{gathered}
\mathrm{x}=\left[\begin{array}{llll}
\mathrm{i}_{\mathrm{ds}} & \mathrm{i}_{\mathrm{qs}} & \phi_{\mathrm{ds}} & \phi_{\mathrm{qs}}
\end{array}\right]^{\mathrm{T}} ; \mathrm{A}=\left[\begin{array}{cccc}
-\frac{1}{\sigma}\left(\frac{\tau_{\mathrm{s}}+\tau_{\mathrm{r}}}{\tau_{\mathrm{s}} \tau_{\mathrm{r}}}\right) & \omega_{\mathrm{sl}} & \frac{1}{\sigma \mathrm{L}_{\mathrm{s}} \tau_{\mathrm{r}}} & \frac{\omega_{\mathrm{r}}}{\sigma \mathrm{L}_{\mathrm{s}}} \\
-\omega_{\mathrm{sl}} & -\frac{1}{\sigma}\left(\frac{\tau_{\mathrm{s}}+\tau_{\mathrm{r}}}{\tau_{\mathrm{s}} \tau_{\mathrm{r}}}\right) & -\frac{\omega_{\mathrm{r}}}{\sigma \mathrm{L}_{\mathrm{s}}} & \frac{1}{\mathrm{~L}_{\mathrm{s}} \tau_{\mathrm{r}}} \\
-\mathrm{R}_{\mathrm{s}} & 0 & 0 & \omega_{\mathrm{s}} \\
0 & \mathrm{R}_{\mathrm{s}} & -\omega_{\mathrm{s}} & 0
\end{array}\right] ; \\
\mathrm{u}=\left[\begin{array}{ll}
\mathrm{v}_{\mathrm{ds}} & \mathrm{v}_{\mathrm{qs}}
\end{array}\right]^{\mathrm{T}} ; \mathrm{y}=\left[\begin{array}{ll}
\mathrm{i}_{\mathrm{ds}} & \mathrm{i}_{\mathrm{qs}}
\end{array}\right]^{\mathrm{T}} ; \mathrm{C}=\left[\begin{array}{cccc}
1 & 0 & 0 & 0 \\
0 & 1 & 0 & 0
\end{array}\right]^{\mathrm{T}} \text { and } \mathrm{B}=\frac{1}{\sigma \mathrm{L}_{\mathrm{s}}} \mathrm{C}^{\mathrm{T}}
\end{gathered}
$$

Equation (11) can be linearised around an operating point as:

$$
\left\{\begin{array}{l}
\Delta\left(\frac{\mathrm{dx}}{\mathrm{dt}}\right)=\mathrm{A} \Delta \mathrm{x}+\Delta \mathrm{Ax}_{0} \\
\Delta \mathrm{y}=\mathrm{C} \Delta \mathrm{x}=\mathrm{C}(\mathrm{pI}-\mathrm{A})^{-1} \Delta \mathrm{Ax}_{0}
\end{array}\right.
$$

where $\mathrm{x}_{0}=\left[\begin{array}{llll}\mathrm{i}_{\mathrm{ds} 0} & \mathrm{i}_{\mathrm{qs} 0} & \phi_{\mathrm{ds} 0} & \phi_{\mathrm{qs} 0}\end{array}\right]^{\mathrm{T}}$ and $\Delta \mathrm{A}=\left[\begin{array}{cccc}0 & -1 & 0 & \frac{1}{\sigma \mathrm{L}_{\mathrm{s}}} \\ 1 & 0 & -\frac{1}{\sigma \mathrm{L}_{\mathrm{s}}} & 0 \\ 0 & 0 & 0 & 0 \\ 0 & 0 & 0 & 0\end{array}\right] \Delta \omega_{\mathrm{r}}$

Considering that:

$$
\begin{aligned}
(p I-A)^{-1} & =\frac{\operatorname{adj}(p I-A)}{|p I-A|} \\
\operatorname{adj}(p I-A) & =\left[\begin{array}{llll}
a_{11} & a_{12} & a_{13} & a_{14} \\
a_{21} & a_{22} & a_{23} & a_{24} \\
a_{31} & a_{32} & a_{33} & a_{34} \\
a_{41} & a_{42} & a_{43} & a_{44}
\end{array}\right]
\end{aligned}
$$

$a_{i j}$ for $i=1,2, \ldots, 4$ and $j=1,2, \ldots, 4$ then and by using Eq. (11)

$$
\begin{aligned}
& \frac{\Delta \mathrm{i}_{\mathrm{ds}}}{\Delta \omega_{\mathrm{r}}}=\frac{\mathrm{a}_{12} \mathrm{i}_{\mathrm{ds} 0}-\mathrm{a}_{11} \mathrm{i}_{\mathrm{qs} 0}-\frac{1}{\sigma \mathrm{L}_{\mathrm{s}}} \mathrm{a}_{12} \phi_{\mathrm{ds} 0}}{|\mathrm{pI}-\mathrm{A}|} \\
& \frac{\Delta \mathrm{i}_{\mathrm{qs}}}{\Delta \omega_{\mathrm{r}}}=\frac{\mathrm{a}_{22} \mathrm{i}_{\mathrm{ds} 0}-\mathrm{a}_{21} \mathrm{i}_{\mathrm{qs} 0}-\frac{1}{\sigma \mathrm{L}_{\mathrm{s}}} \mathrm{a}_{23} \phi_{\mathrm{ds} 0}}{|\mathrm{pI}-\mathrm{A}|}
\end{aligned}
$$

The references $d$ - and $q$-axis command voltages are given by the following equations: 


$$
\begin{aligned}
& \mathrm{v}_{\mathrm{ds}}^{*}=\sigma \mathrm{L}_{\mathrm{s}}\left(\mathrm{p}+\frac{\tau_{\mathrm{s}}+\tau_{\mathrm{r}}}{\sigma \tau_{\mathrm{s}} \tau_{\mathrm{r}}}\right) \mathrm{i}_{\mathrm{ds}}-\frac{\phi_{\mathrm{s}}}{\tau_{\mathrm{r}}}-\sigma \mathrm{L}_{\mathrm{s}} \omega_{\mathrm{sl}} \mathrm{i}_{\mathrm{qs}} \\
& \mathrm{v}_{\mathrm{qs}}^{*}=\sigma \mathrm{L}_{\mathrm{s}}\left(\mathrm{p}+\frac{\tau_{\mathrm{s}}+\tau_{\mathrm{r}}}{\sigma \tau_{\mathrm{s}} \tau_{\mathrm{r}}}\right) \mathrm{i}_{\mathrm{qs}}+\frac{\omega_{\mathrm{r}}}{\tau_{\mathrm{r}}} \phi_{\mathrm{s}}+\sigma \mathrm{L}_{\mathrm{s}} \omega_{\mathrm{sl}} \mathrm{i}_{\mathrm{ds}}
\end{aligned}
$$

Note that there is a coupling between the voltage and the current in $v_{\text {ds }}$ and $v_{\text {qs }}$ equations. Indeed, the direct component of the voltage is coupled with the quadrature component of the current and vice versa. However, a compensation method is used to avoid the coupling problem, so that the $v_{\mathrm{ds}}$ component can control only the current $i_{\mathrm{ds}}$ and thereafter the stator flux amplitude, as far as the $v_{\mathrm{qs}}$ component, can only control the current $i_{\text {qs }}$ and thereafter the electromagnetic torque.

The decoupling procedure consists of adding the $E_{d}$ and $E_{q}$ voltages to Eqs (16) and (17). $E_{d}$ and $E_{q}$ are called decoupling $\mathrm{d}$ and $\mathrm{q}$-back electromotive force. When the decoupling method is implemented, the $v_{\mathrm{ds}}$ and $v_{\mathrm{qs}}$ components equations become:

$$
\begin{aligned}
& \mathrm{v}_{\mathrm{d}}=\mathrm{v}_{\mathrm{ds}}+\mathrm{E}_{\mathrm{d}}=\sigma \mathrm{L}_{\mathrm{s}}\left(\mathrm{p}+\frac{\tau_{\mathrm{s}}+\tau_{\mathrm{r}}}{\sigma \tau_{\mathrm{s}} \tau_{\mathrm{r}}}\right) \mathrm{i}_{\mathrm{ds}} \\
& \mathrm{v}_{\mathrm{q}}=\mathrm{v}_{\mathrm{qs}}+\mathrm{E}_{\mathrm{q}}=\sigma \mathrm{L}_{\mathrm{s}}\left(\mathrm{p}+\frac{\tau_{\mathrm{s}}+\tau_{\mathrm{r}}}{\sigma \tau_{\mathrm{s}} \tau_{\mathrm{r}}}\right) \mathrm{i}_{\mathrm{qs}}
\end{aligned}
$$

where $\mathrm{E}_{\mathrm{d}}=\frac{\phi_{\mathrm{s}}}{\tau_{\mathrm{r}}}+\sigma \mathrm{L}_{\mathrm{s}} \omega_{\mathrm{sl}} \mathrm{i}_{\mathrm{qs}}$ and $\mathrm{E}_{\mathrm{q}}=-\frac{\omega_{\mathrm{r}}}{\tau_{\mathrm{r}}} \phi_{\mathrm{s}}-\sigma \mathrm{L}_{\mathrm{s}} \omega_{\mathrm{sl}} \mathrm{i}_{\mathrm{ds}}$

Thus, it is possible to control the components $d$-q current with a PI controller. This choice provides an improvement of the dynamic performances and reduces the static error. However, the proportional and integral gains of PI $d$ - $q$ axis current controller $K_{i p}$ and $K_{i i}$ are indicated in Figure 3. $G_{d}(p)$ and $G_{q}(p)$ are the no decoupling electrical d_q axis transfer functions of IM.

where

$$
\mathrm{G}_{d}(p)=\mathrm{G}_{\mathrm{q}}(\mathrm{p})=\frac{\mathrm{K}_{\mathrm{c}}}{1+\tau_{\mathrm{c}} \mathrm{p}}=\frac{\frac{\tau_{\mathrm{s}} \tau_{\mathrm{r}}}{\mathrm{L}_{\mathrm{s}}\left(\tau_{\mathrm{s}}+\tau_{\mathrm{r}}\right)}}{1+\frac{\sigma \tau_{\mathrm{s}} \tau_{\mathrm{r}}}{\left(\tau_{\mathrm{s}}+\tau_{\mathrm{r}}\right)} \mathrm{p}}
$$

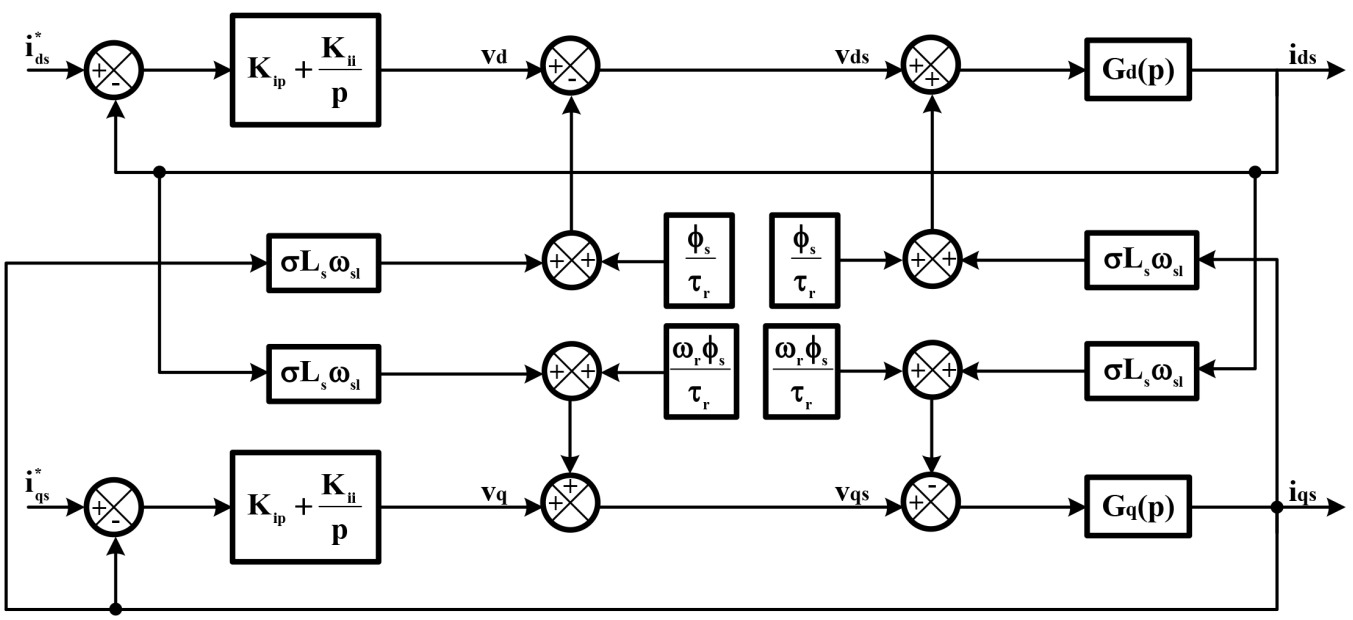

Fig. 3. Block diagram of the decoupling method with PI controller. 
With: $\mathrm{K}_{\mathrm{c}}=\frac{\tau_{\mathrm{s}} \tau_{\mathrm{r}}}{\mathrm{L}_{\mathrm{s}}\left(\tau_{\mathrm{s}}+\tau_{\mathrm{r}}\right)}$ and $\tau_{\mathrm{c}}=\frac{\sigma \tau_{\mathrm{s}} \tau_{\mathrm{r}}}{\left(\tau_{\mathrm{s}}+\tau_{\mathrm{r}}\right)}$

From Figure 3

$$
\begin{aligned}
& \mathrm{v}_{\mathrm{ds}}=\mathrm{z}\left(\mathrm{i}_{\mathrm{ds}}^{*}-\mathrm{i}_{\mathrm{ds}}\right)-\sigma \mathrm{L}_{\mathrm{s}} \omega_{\mathrm{sl}} \mathrm{i}_{\mathrm{qs}}-\frac{\phi_{\mathrm{s}}}{\tau_{\mathrm{r}}} \\
& \mathrm{v}_{\mathrm{qs}}=\mathrm{z}\left(\mathrm{i}_{\mathrm{qs}}^{*}-\mathrm{i}_{\mathrm{qs}}\right)+\sigma \mathrm{L}_{\mathrm{s}} \omega_{\mathrm{sl}} \mathrm{i}_{\mathrm{ds}}-\frac{\omega_{\mathrm{r}} \phi_{\mathrm{s}}}{\tau_{\mathrm{r}}}
\end{aligned}
$$

where $z$ is the transfer functions of the current controller: $z=K_{i p}+\frac{K_{i i}}{p}$

The linearisation of Eqs (22) and (23) gives:

$$
\begin{aligned}
& \Delta \mathrm{v}_{\mathrm{ds}}=-\mathrm{z} \Delta \mathrm{i}_{\mathrm{ds}}-\sigma \mathrm{L}_{\mathrm{s}} \omega_{\mathrm{sl}} \Delta \mathrm{i}_{\mathrm{qs}} \\
& \Delta \mathrm{v}_{\mathrm{qs}}=-\mathrm{z} \Delta \mathrm{i}_{\mathrm{qs}}+\sigma \mathrm{L}_{\mathrm{s}} \omega_{\mathrm{sl}} \Delta \mathrm{i}_{\mathrm{ds}}+\frac{\phi_{\mathrm{s}}}{\tau_{\mathrm{r}}} \Delta \omega_{\mathrm{r}}
\end{aligned}
$$

The error function in R-MRAS is obtained as:

$$
\varepsilon=\mathrm{R}_{1}-\mathrm{R}_{4}=\frac{\mathrm{v}_{\mathrm{ds}}}{\mathrm{i}_{\mathrm{ds}}}-\frac{\mathrm{v}_{\mathrm{qs}}}{\mathrm{i}_{\mathrm{qs}}}+\frac{\mathrm{L}_{\mathrm{s}} \mathrm{R}_{\mathrm{r}}}{\mathrm{L}_{\mathrm{r}}} \frac{\phi_{\mathrm{s}}}{\phi_{\mathrm{s}}-\sigma \mathrm{L}_{\mathrm{s}} \mathrm{i}_{\mathrm{ds}}}+\omega_{\mathrm{r}} \frac{\phi_{\mathrm{s}}}{\mathrm{i}_{\mathrm{qs}}}
$$

According to the general structure of the adaptation mechanism, the speed estimation $\omega_{\mathrm{r}}$ is a function of error $\varepsilon$.

The expression of $\varepsilon$ is free from stator resistance. As a result, the proposed strategy does not need any sort of flux computation and thus makes the scheme insensitive to the problem's integration of the back electromotive force of the machine, enabling low or zero speed estimation quite accurate.

In contrast, Agrebi Zorgani et al. (2018) replaced the pure integrator with a programmable-cascaded low-pass filter (PCLPF) to resolve the problem of flux estimation. Unfortunately, the computation time of the above method is heavy.

To investigate the dynamic response of the R-MRAS rotor speed estimation, it is necessary to linearise the error equation for a small deviation around a working point. Then, the deviations of the error $\varepsilon$ are presented by:

$$
\begin{aligned}
& \partial \varepsilon=\left.\frac{\partial \varepsilon}{\partial \mathrm{i}_{\mathrm{ds}}}\right|_{0} \mathrm{di}_{\mathrm{ds}}+\left.\frac{\partial \varepsilon}{\partial \mathrm{i}_{\mathrm{qs}}}\right|_{0} \mathrm{di}_{\mathrm{qs}}+\left.\frac{\partial \varepsilon}{\partial \mathrm{v}_{\mathrm{ds}}}\right|_{0} \mathrm{dv}_{\mathrm{ds}}+\left.\frac{\partial \varepsilon}{\partial \mathrm{v}_{\mathrm{qs}}}\right|_{0} \mathrm{dv}_{\mathrm{qs}}+\left.\frac{\partial \varepsilon}{\partial \omega_{\mathrm{r}}}\right|_{0} \mathrm{~d} \omega_{\mathrm{r}} \\
& \Delta \varepsilon=\mathrm{b}_{1} \Delta \mathrm{i}_{\mathrm{ds}}+\mathrm{b}_{2} \Delta \mathrm{i}_{\mathrm{qs}}+\mathrm{b}_{3} \Delta \hat{\omega}_{\mathrm{r}}
\end{aligned}
$$

where

$$
\begin{aligned}
& \mathrm{b}_{1}=-\frac{\mathrm{v}_{\mathrm{ds} 0}}{\mathrm{i}_{\mathrm{ds} 0}^{2}}-\frac{\sigma \mathrm{R}_{\mathrm{r}} \mathrm{L}_{\mathrm{s}}^{2} \phi_{\mathrm{s} 0}}{\mathrm{~L}_{\mathrm{r}}\left(\phi_{\mathrm{s} 0}-\sigma \mathrm{L}_{\mathrm{s}} \mathrm{i}_{\mathrm{ds} 0}\right)^{2}} \mathrm{i}_{\mathrm{qs} 0}-\frac{\mathrm{z}}{\mathrm{i}_{\mathrm{ds} 0}}-\frac{\sigma \mathrm{L}_{\mathrm{s}} \omega_{\mathrm{s} 10}}{\mathrm{i}_{\mathrm{qs} 0}} \\
& \mathrm{~b}_{2}=\frac{\mathrm{v}_{\mathrm{qs} 0}}{\mathrm{i}_{\mathrm{qs} 0}^{2}}-\frac{\sigma \mathrm{R}_{\mathrm{r}} \mathrm{L}_{\mathrm{s}} \phi_{\mathrm{s} 0}}{\mathrm{~L}_{\mathrm{r}}\left(\phi_{\mathrm{s} 0}-\sigma \mathrm{L}_{\mathrm{s}} \mathrm{i}_{\mathrm{ds} 0}\right)} \mathrm{i}_{\mathrm{qs} 0}+\frac{\mathrm{z}}{\mathrm{i}_{\mathrm{qs} 0}}-\frac{\sigma \mathrm{L}_{\mathrm{s}} \omega_{\mathrm{s} 10}}{\mathrm{i}_{\mathrm{ds} 0}}-\frac{\omega_{\mathrm{r} 0} \phi_{\mathrm{s} 0}}{\mathrm{i}_{\mathrm{qs} 0}} \\
& \mathrm{~b}_{3}=\frac{\phi_{\mathrm{s} 0}}{\mathrm{i}_{\mathrm{qs} 0}}\left(1-\frac{1}{\tau_{\mathrm{r}}}\right)
\end{aligned}
$$

The closed-loop block diagram of the R-MRAS is presented in Figure 4. The transfer function G can be expressed as:

$$
\mathrm{G}=\frac{\Delta \varepsilon}{\Delta \hat{\omega}_{\mathrm{r}}}=\mathrm{b}_{1} \frac{\Delta \mathrm{i}_{\mathrm{ds}}}{\Delta \hat{\omega}_{\mathrm{r}}}+\mathrm{b}_{2} \frac{\Delta \mathrm{i}_{\mathrm{qs}}}{\Delta \hat{\omega}_{\mathrm{r}}}+\mathrm{b}_{3}
$$


Using Eq. (29), the closed-loop transfer function of the R-MRAS is obtained as:

$$
\frac{\hat{\omega}_{\mathrm{r}}}{\omega_{\mathrm{r}}}=\frac{G(p)\left(\mathrm{K}_{\mathrm{p}_{-} \text {MRAS }}+\frac{\mathrm{K}_{\mathrm{i}_{-} \text {MRAS }}}{\mathrm{p}}\right)}{1+\mathrm{G}(\mathrm{p})\left(\mathrm{K}_{\mathrm{p}_{-} \text {MRAS }}+\frac{\mathrm{K}_{\mathrm{i}_{-} \text {MRAS }}}{\mathrm{p}}\right)}
$$

The adaptation mechanism is built around a PI regulator, which allows the estimated quantities to converge to the exact values. Figure 4 shows the synthesis result of the speed corrector.

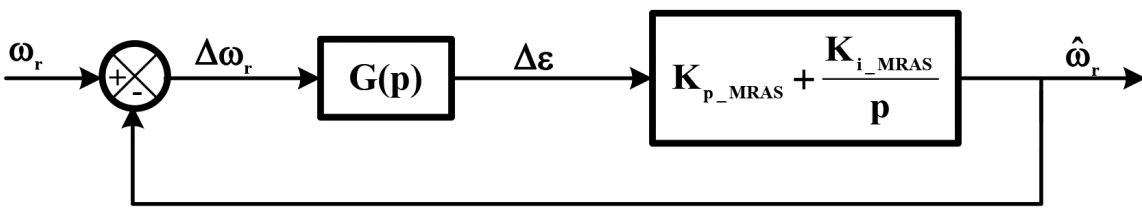

Fig. 4. Closed-loop block diagram of the R-MRAS

\subsection{Stability analysis}

To underscore the influence of the real speed on the stability of the estimator, the place of the poles and the zeroes for various values of $\omega_{\mathrm{r}}$ are presented. For a rotor speed variation in the interval from 0 to $157 \mathrm{rad} / \mathrm{s}$, the R-MRAS estimator poles' locations are shown in Figure 5.

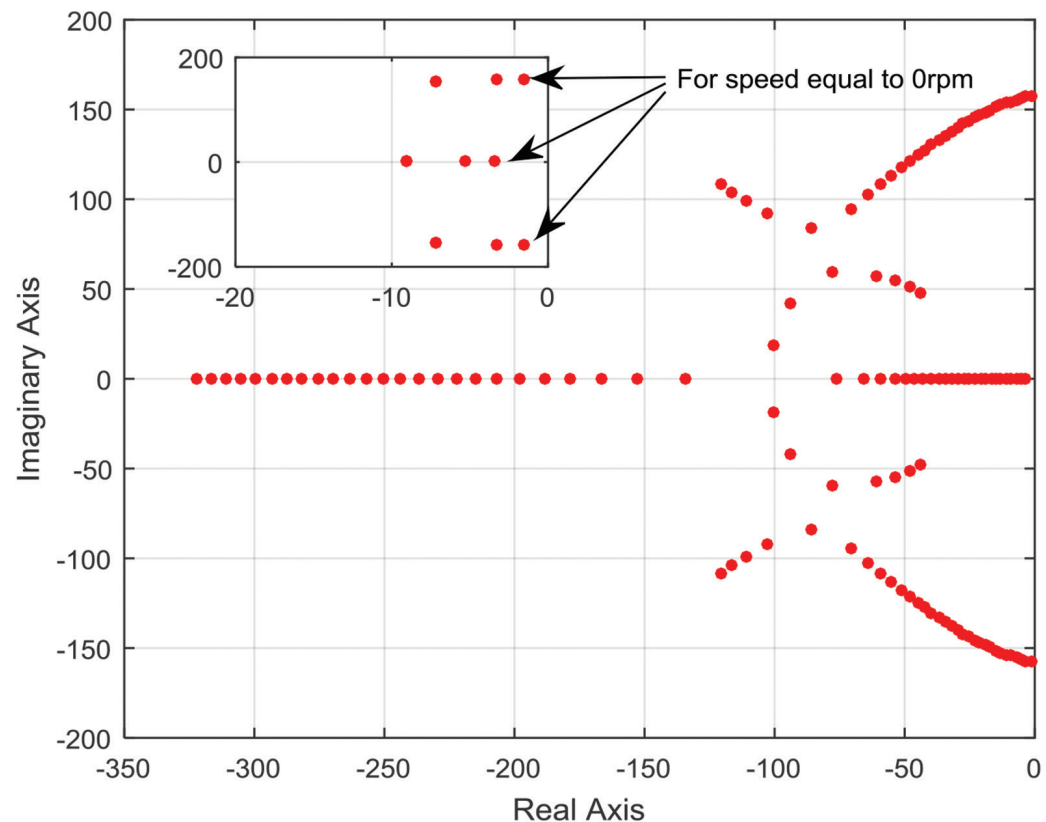

Fig. 5. Placement of poles and zeros for different speed values of the R-MRAS estimator.

We notice that all these poles are complex conjugates and have a negative real part. Moreover, every speed point has three poles.

\section{Simulation Results}

The performance of the proposed R-MRAS for speed sensorless vector-controlled drive is verified in MATLAB/ Simulink. The simulation results are presented for the following test cases. 


\subsection{Trapezoidal response}

The speed tracking performance of the proposed scheme is tested for a trapezoidal reference speed from $-239 \mathrm{rpm}$ to $700 \mathrm{rpm}$ followed by the application of a load torque at $t=3 \mathrm{~s}$, and the abolition of the latter at $t=5 \mathrm{~s}$. The estimated and actual speeds are found to track the reference speed satisfactorily (Figure 6a). However, the error between the real and the estimated speed is presented in Figure $6 \mathrm{~b}$; it is noteworthy to mention that, in steady-state, the error does not exceed the value of $1.2 \mathrm{rpm}(0.17 \%)$. Figure $6 \mathrm{c}$ shows the shape of the $d$-axis and $q$-axis stator currents curves. Furthermore, the proportionality between the $q$-axis stator current and the electromagnetic torque has been confirmed in Figure $6 \mathrm{~d}$. The currents $i_{\mathrm{as}}, i_{\mathrm{bs}}$ and $i_{\mathrm{cs}}$ and voltages $v_{\mathrm{as}}, v_{\mathrm{bs}}$ and $v_{\mathrm{cs}}$ in the stator are presented in Figure 6e and Figure 6f, respectively. Their forms show that they are sinusoidal and phase-shifted by one relative to each other of $2 \frac{\pi}{3}$. Moreover, the flux orientation in the rotating reference frame is well maintained throughout the simulation time (Figure $6 \mathrm{~g}$ ). Figure $6 \mathrm{~h}$ shows the magnitude of the machine flux in the stationary reference frame (i.e. $\phi_{\mathrm{ds}}$ and $\phi_{\mathrm{ds}}$ ), which is maintained throughout the operation.

According to those simulation results, the sensorless IM drive based on the MRAS strategy utilising a fictitious resistance presents a better steady-state constancy than the papers presented by (Agrebi Zorgani et al., 2012) and (Jouili et al., 2015). However, the error between the estimated and real speed value of this strategy is less

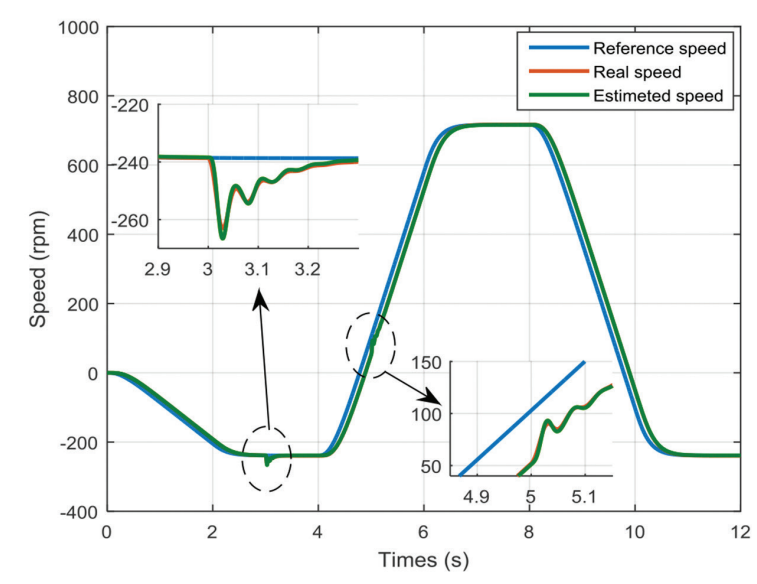

(a)

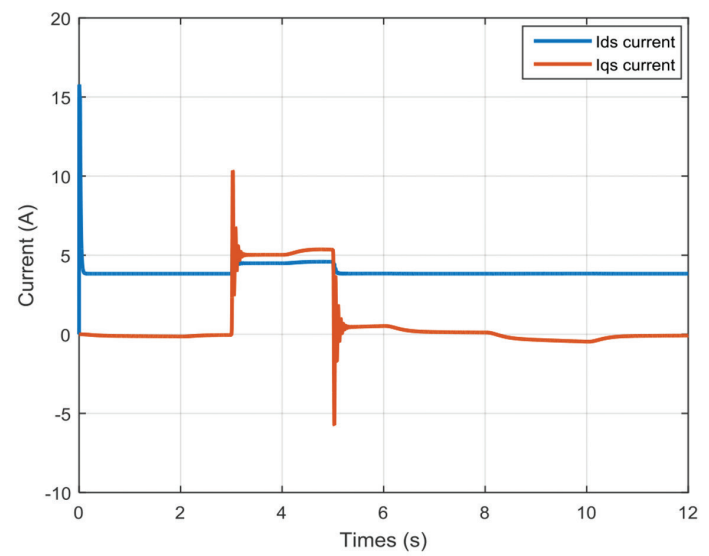

(c)

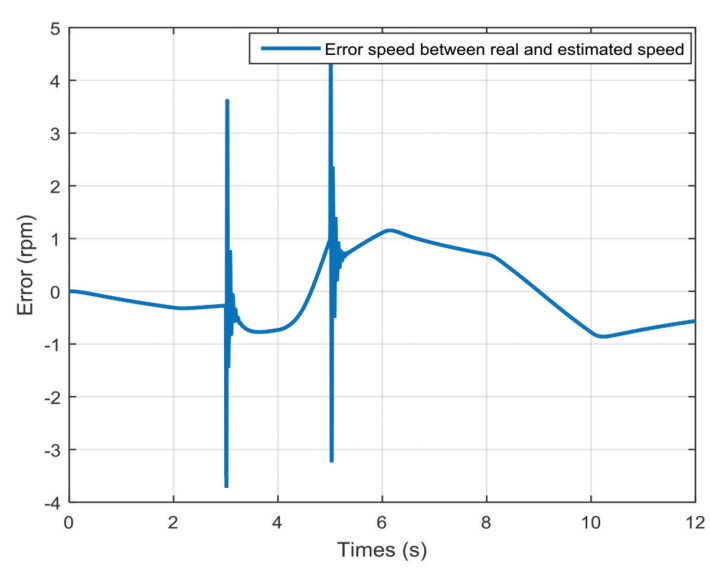

(b)

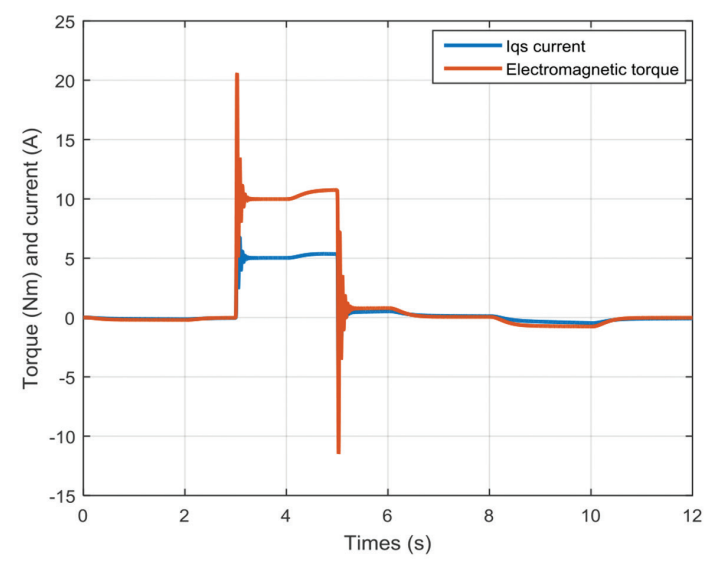

(d) 


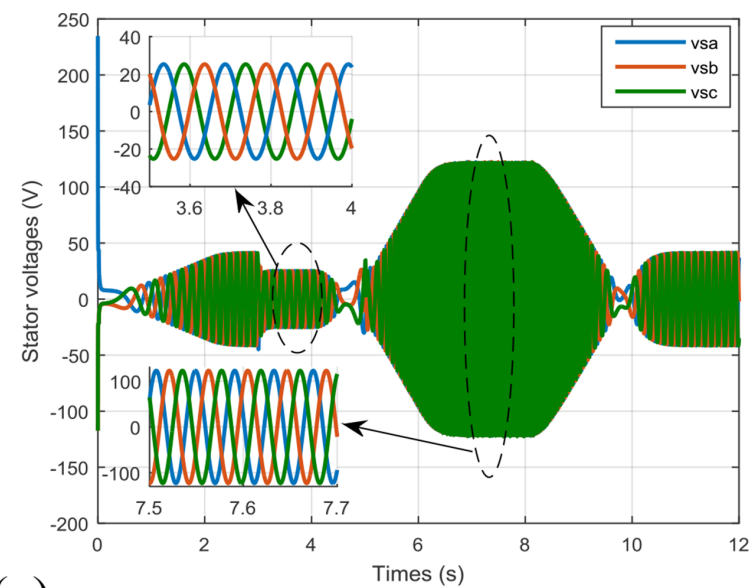

(e)

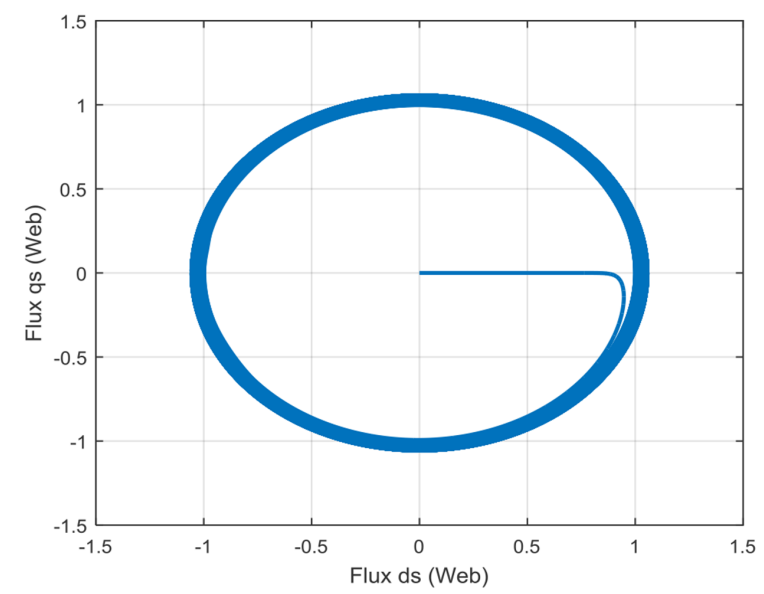

(g)

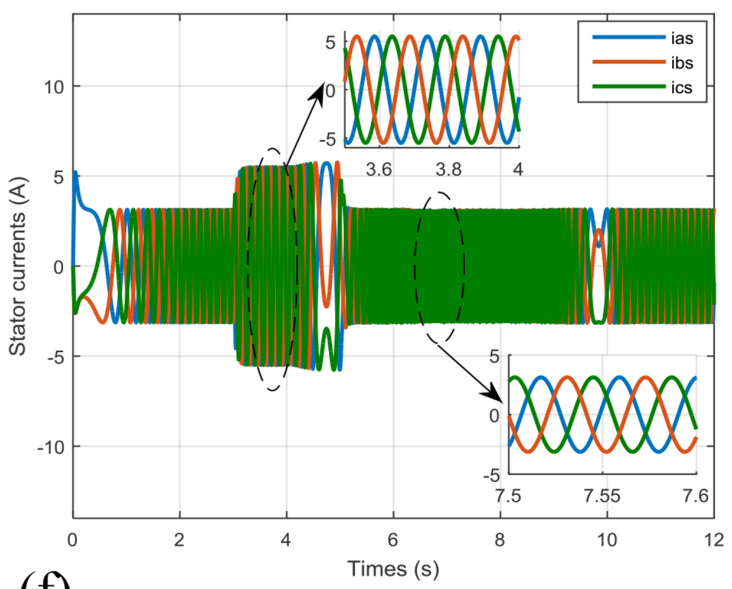

(f)

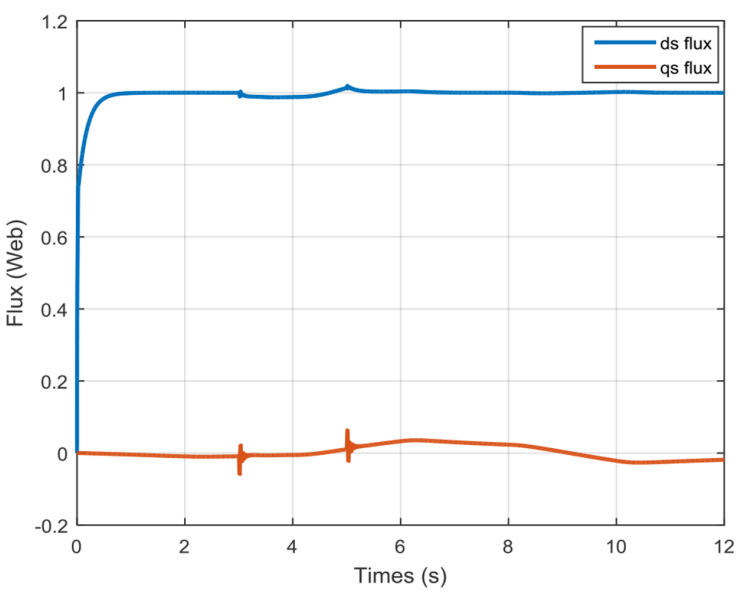

(h)

Fig. 6. Simulation results for a trapezoidal reference speed from $-239 \mathrm{rpm}$ to $700 \mathrm{rpm}$.

than $0.17 \%$, while this value is less than $0.3 \%$ and $0.5 \%$ in (Agrebi Zorgani et al., 2012) and (Jouili et al., 2015), respectively.

In addition, in the comparative study of this article, we notice that the proposed method still keeps its robustness and its good performances compared to the two other schemes when applying the load torque in the transient regime. However, Agrebi Zorgani et al. (2012) and Jouili et al. (2015) apply the load torque only in the steady-state.

\subsection{Zero and low-speed operation}

To show the robustness of the R-MRAS sensorless ISFOC, a low-speed reference with a reverse rotation speed $(0 \rightarrow 20 \rightarrow-20 \rightarrow 0 \mathrm{rpm})$ is applied. It is noticeable that the estimated speed follows the reference speed quite perfectly even at a zero speed and low speed of 20 and $-20 \mathrm{rad} / \mathrm{s}$ (Figure 7a). The error between estimated and real speed as given in Figure $7 \mathrm{~b}$; the value of this error is less than $0.05 \mathrm{rd} / \mathrm{s}$ in the steadystate. The flux orientation is also well maintained (Figure 7e), and it is clear that their shapes verify the correct operation of the ISFOC. These results confirm the satisfactory operation of the proposed scheme in the lowspeed region. 


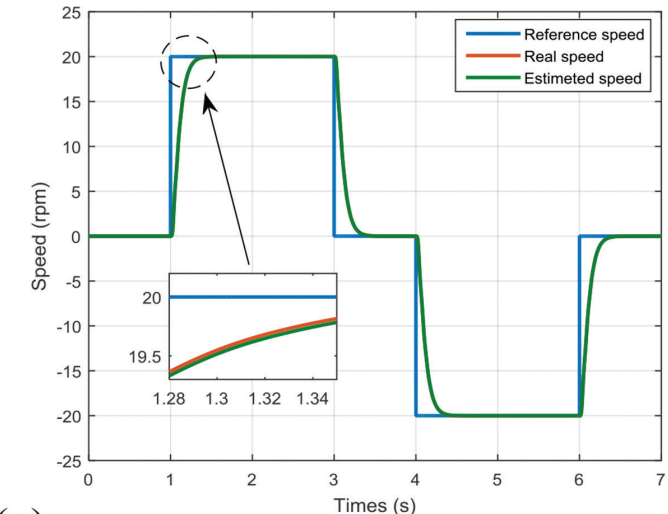

(a)

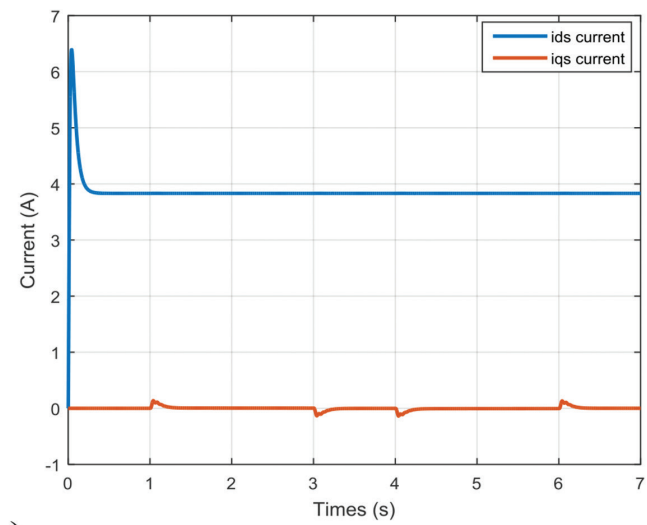

(c)

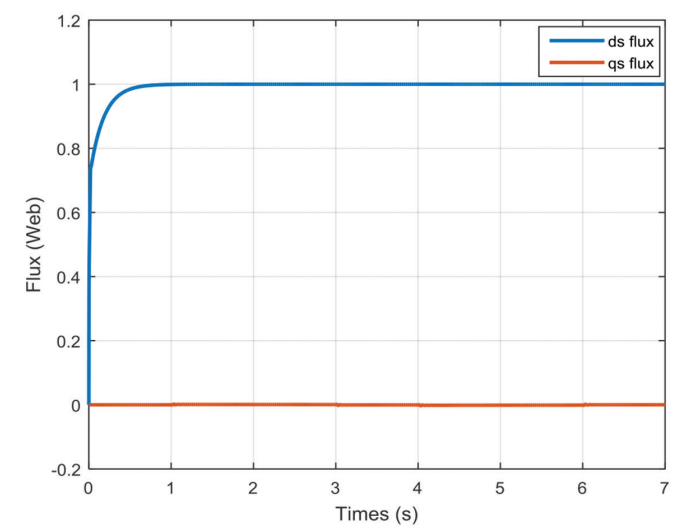

(e)

Fig. 7. Simulation results for a zero and low-speed operation with inverting direction.

\subsection{Nominal speed}

During the simulation shown in Figure 8, at nominal speed, the torque is applied with $10 \mathrm{Nm}$ at $t=3 \mathrm{~s}$ and cancelled at $t=5 \mathrm{~s}$. The three trajectories of estimated, real, and reference rotor speed coincide fairly well, and a good coincidence is reached (Figure 8a). In Figure 8b, the estimated rotor speed matches the actual rotor speed of the machine with an error of $0.8 \mathrm{rpm}$. However, the curve of ids and iqs currents are shown in Figure 8c. We also note in Figure $8 \mathrm{~d}$ that the $q$-axis current iqs has the same shape as the electromagnetic torque. Furthermore, Figure $8 \mathrm{f}$ shows that the stator flux is aligned with the $d$-axis ( $\phi d s=\phi s$ and $\phi q s=0)$ with a minor error due to the inaccuracy of the motor parameters.

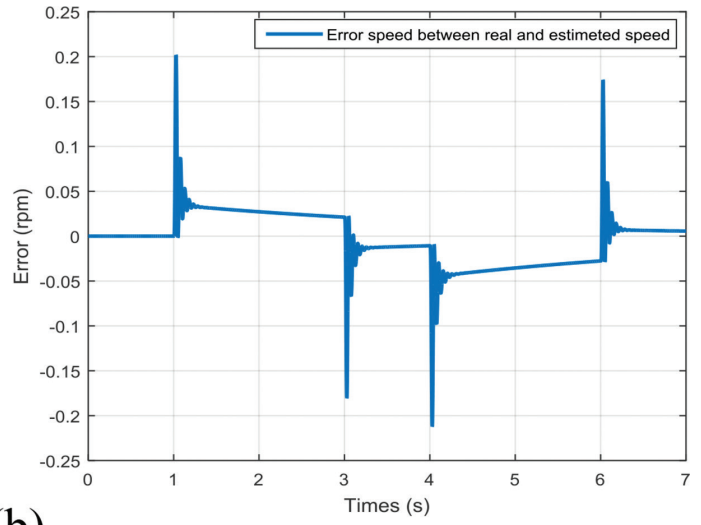

(b)

(d)
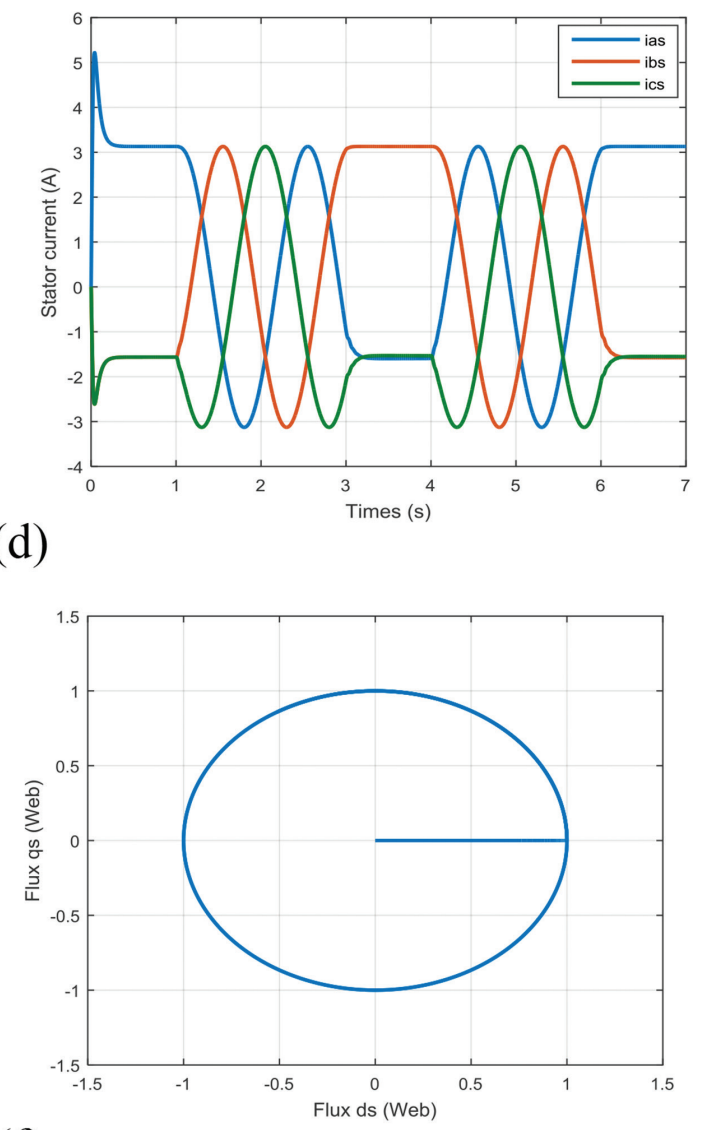

(f) 


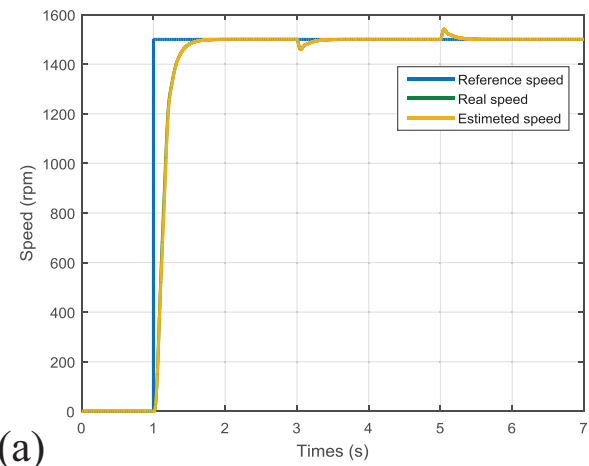

(a)

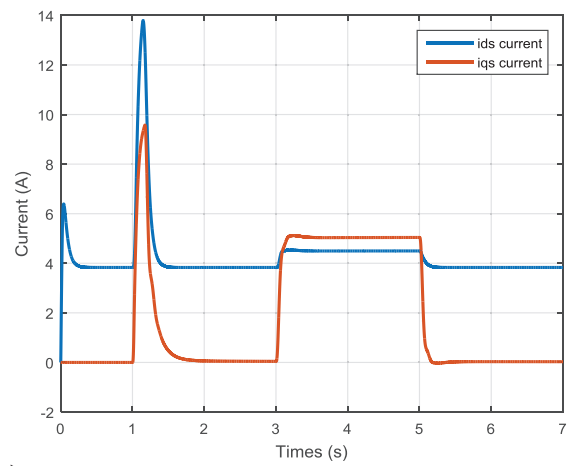

(c)

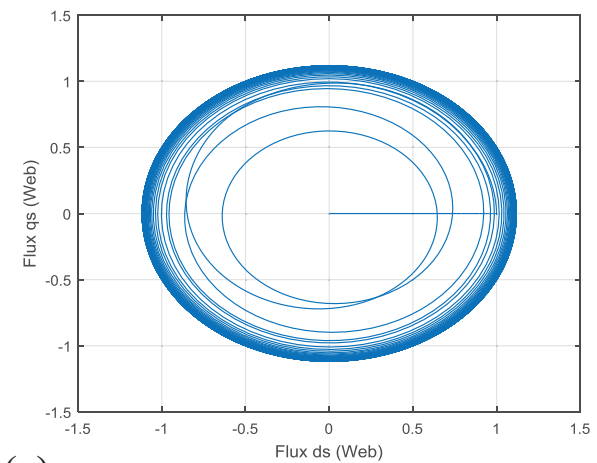

(e)

Fig. 8. Simulation results for a nominal speed.
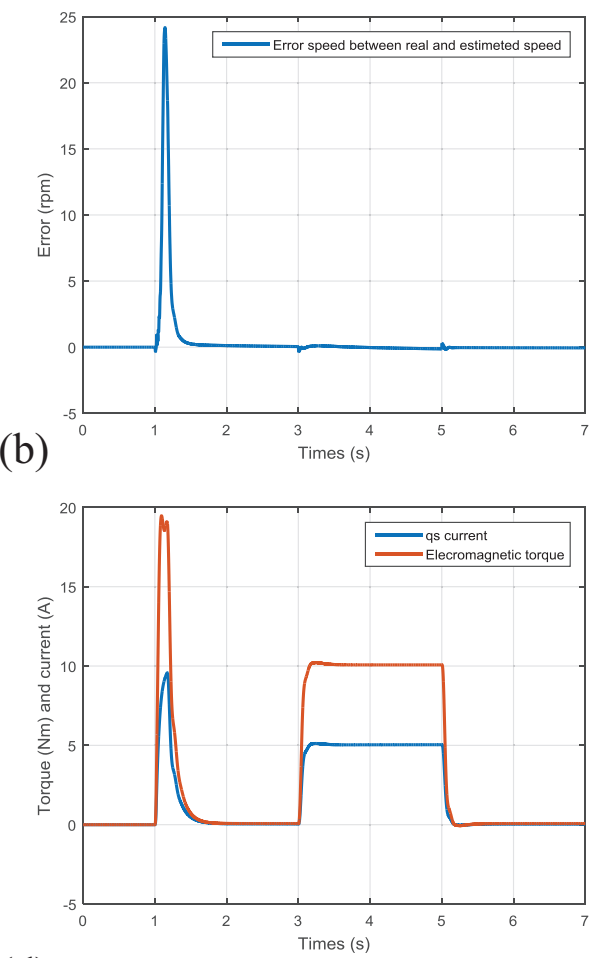

(d)

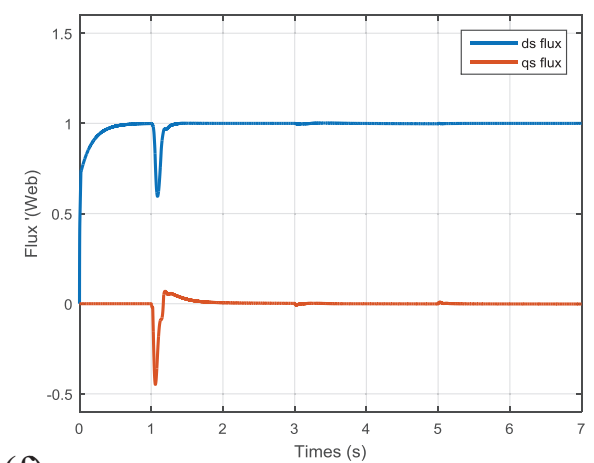

(f)

The obtained result demonstrates that even at the nominal speed, the proposed ISFOC, which is based on the R-MRAS algorithm, still gives a good estimate of rotor speed.

\section{Conclusion}

This article presents a novel MRAS controller for ISFOC motor drive using fictitious resistance $R_{\mathrm{f}}$ as the basic quantity. In the R-MRAS approach, the instantaneous and steady-state values of $R_{\mathrm{f}}$ in the reference and adaptive models respectively are employed. The proposed strategy does not need any kind of flux computation and eliminates derivative terms from the adaptive model, thereby making it suitable for low-speed operation. The simulation study confirms the satisfactory working of the proposed controller in a wide speed range up to the nominal speed with a negligible error between the estimated and actual speed. Moreover, the analysed closed-loop stability of the presented method has also been proved. Further, all simulation results indicate the effectiveness of the proposed method and thus prove the high dynamic performances of the developed drive system. 


\section{References}

Abhisek, P. and Sukanta, D. (2016). A New Sensorless Speed Estimation Strategy for Induction Motor Driven Electric Vehicle with Energy Optimization Scheme. $1^{\text {st }}$ IEEE International Conference on Power Electronics. Intelligent Control and Energy Systems, Delhi, India, 4-6 July 2016, pp. 1-6.

Agrebi Zorgani, Y., Jouili, M., Koubaa, Y. and Boussak, M. (2018). A Very Low Speed Sensorless Control Induction Motor Drive with Online Rotor Resistance Using MRAS Scheme. Power Electronics and Drives, 3(3), 171-186.

Agrebi-Zorgani, Y., Koubaa, Y. and Boussak, M. (2010). Simultaneous Estimation of Speed and Rotor Resistance in Sensorless ISFOC Induction Motor Drive Based on MRAS Scheme. IEEE International Conference on Electrical Machines ICEM, Rome, 6-8 September, pp. 1-6.

Agrebi-Zorgani, Y., Koubaa, Y. and Boussak, M. (2012). Sensorless Speed Control with MRAS for Induction Motor Drive. IEEE International Conference on Electrical Machines ICEM, Marseille, 2-5 September, pp. 2257-2263.

Agrebi-Zorgani, Y., Koubaa, Y. and Boussak, M. (2016). MRAS State Estimator for Speed Sensorless ISFOC Induction Motor Drives with Luenberger Load Torque Estimation. ISA Transactions, 61, pp. 308-317.

Alkorta, P., Barambones, O., Cortajarena, J. A. and Zubizarrreta, A. (2014). Efficient Multivariable Generalized Predictive Control for Sensorless Induction Motor Drives. IEEE Transactions on Industrial Electronics, 61(9), 5126-5134.

Alonge, F., Cangemi, T., D'Ippolito, F., Fagiolini, A. and Sferlazza, A. (2015). Convergence Analysis of Extended Kalman Filter for Sensorless Control of Induction Motor. IEEE Transactions on Industrial Electronics, 62(4), 2341-2352.

Comanescu, M. (2015). A robust sensorless sliding mode observer with speed estimate for the flux magnitude of the induction motor drive. In: 9th International Conference on Compatibility and Power Electronics, Costa da Caparica, Portugal, pp. 224-229.

Dybkowski, M. (2018). Universal Speed and Flux Estimator for Induction Motor. Power Electronics and Drives, AOP. doi: 10.2478/pead-2018-0007.

Dybkowski, M. and Orlowska-Kowalska, T. (2013). Speed sensorless induction motor drive system with MRAS type speed and flux estimator and additional parameter identification. In: 11th IFAC International Workshop on Adaptation and
Learning in Control and Signal Processing, Caen, France, 3-5 July, pp. 33-38.

Farza, M., M'Saad, M., Dorl'eans, Ph. and Massieu, J. F. (2011). High gain observer for sensorless induction motor. In: 18th IFAC World Congress, Milano, Italy, August 28 - September 2, pp. 674-679.

Farza, M., M'Saad, M., Ménard, T., Ltaief, A. and Maatoug, T. (2018). Adaptive Observer Design for A Class of Nonlinear Systems. Application to Speed Sensorless Induction Moto. Automatica, 90, 239-247.

Gao, Q., Asher, G. and Sumner, M. (2013). Implementation of Sensorless Control of Induction Machines Using Only Fundamental PWM Waveforms of A Two-Level Converter. IET Power Electronics, 6(8), 1575-1582.

Gennaro, S. D., Dominguez, J. R. and Meza, M. A. (2014). Sensorless High Order Sliding Mode Control of Induction Motors with Core Loss. IEEE Transactions on Industrial Electronics, 61(6), 2678-2689.

Habibullah, M. and Lu, D. D.-C. (2015). A SpeedSensorless FS-PTC of Induction Motors Using Extended Kalman Filters. IEEE Transactions on Industrial Electronics, 62(11), 6765-6778.

Jouili, M., Agrebi, Y., Koubaa, Y. and Boussak, M. (2015). A Stability Analysis of Simultaneous Estimation of Speed and Stator Resistance for Sensorless IRFOC Induction Motor Drives. International Journal of Sciences and Techniques of Automatic Control \& Computer Engineering IJ-STA, 9(1), 2026-2034.

Maiti, S., and Chakraborty, C. H. (2010). A New Instantaneous Reactive Power Based MRAS For Sensorless Induction Motor Drive. Simulation Modelling Practice And Theory, 18(9), 1314-1326.

Matic, P. R., Gecic, M. A., Lekic, D. M. and Marcetic, D. P. (2015). Thermal Protection of Vector-Controlled IM Drive. IEEE Transactions on Industrial Electronics, 62(4), 2082-2089.

Mezouar, A., Fellah, M. K. and Hadjeri, S. (2008). Adaptive Sliding-Mode-Observer for Sensorless Induction Motor Drive Using Two-Time-Scale Approach. Simulation Modelling Practice and Theory, 16(9), 1323-1336.

Niasar, A. H. and Khoei, H. R. (2015). Sensorless Direct Power Control of Induction Motor Drive Using Artificial Neural Network. Advances in Artificial Neural Systems, Article ID 318589.

Orlowska-kowalska, T. and Dybkowski, M. (2010). StatorCurrent-Based MRAS Estimator for a Wide Range Speed-Sensorless IM drive. IEEE Transactions on Industrial Electronics, 57(4), 1296-1308. 
Popovic, V. M., Gecic, M. A., Vasic, V. V., Oros, D. V. and Marcetic, D. P. (2014). Evaluation of Luenberger observer based sensorless method for IM. International Symposium on International Electronics, INDEL, 6-8 November, pp. 128-133.

Rashed, M. and Stronach, A. F. (2004). A Stable Back-EMF MRAS-Based Sensorless Low Speed Induction Motor Drive Insensitive to Stator Resistance Variation. IEE Proceedings - Electric Power Applications, 151(6), 685-693.

Rayyam, M. and Zazi, M. (2019). A Novel Metaheuristic Model-Based Approach for Accurate Online Broken Bar Fault Diagnosis in Induction Motor Using Unscented Kalman Filter and ant Lion Optimizer. Transactions of the Institute of Measurement and Control, 42(8), 1537-1546.

Thuy Pham, N., Phu Nguyen, D. and Huu Nguyen, K. (2018). An Improved Neural Network SC_MRAS Speed Observer in Sensorless Control for Six
Phase Induction Drives. WSEAS Transactions on Systems and Control, I(13), 364-374.

Urbański, K. (2014). Comparison of methods for back EMF estimation at low speed for PMSM Drive. In: 16th International Conference on Mechatronics Mechatronika, pp. 32-37.

Verma, R., Verma, V. and Chakraborty, C. (2014). ANN based sensorless vector controlled induction motor drive suitable for four quadrant operation. In: Proceeding of the 2014 IEEE Students' Technology Symposium, Kharagpur, pp. 182-187.

Wang, F. (2014). Encoderless Finite-State Predictive Torque Control for Induction Machine with Acompensated MRAS. IEEE Transactions on Industrial Informatics, 10(2), 1097-1106.

Yoon, Y. D. and Sul, S. K. (2014). Sensorless Control for Induction Machines Based on Square-Wave Voltage Injection. IEEE Transactions on Power Electronics, 29(7), 3637-3645. 


\section{APPENDIX}

List of motor specification and parameters:

$380 \mathrm{~V}, 3 \mathrm{KW}, 4$ poles, $1430 \mathrm{rpm}, \mathrm{Rs}=2.3 \Omega ; \mathrm{Rr}=1.55 \Omega$; Ls=Lr=0.261 H; M=0.245 H; f=0.002 Nm s/rd; J=0.03 kg. m2.

\section{Nomenclature}

$\mathbf{v}_{\mathrm{ds}}, \mathbf{v}_{\mathrm{qs}}, \mathbf{i}_{\mathrm{ds}}, \mathbf{i}_{\mathrm{qs}} \mathrm{d}$, q- axis stator voltage and current components

$\Phi_{\mathrm{ds}}, \boldsymbol{\Phi}_{\mathrm{qs}} \mathrm{d}$, q-axis stator flux components

$\mathbf{R}_{r}, \mathbf{R}_{\mathrm{s}}$ Rotor and stator resistance

$\mathbf{L}_{r}, \mathbf{L}_{\mathbf{s}}$ Rotor and stator self-inductance

M Mutual inductance

$\mathbf{n}_{\mathrm{p}}$ Number of pole pairs

$\mathbf{p}=\frac{\mathbf{d}}{\mathbf{d t}}$ Differential operator

$\boldsymbol{\omega}_{\mathrm{s}}, \boldsymbol{\omega}_{\mathrm{r}}$ Synchronous and rotor angular speed

$\boldsymbol{\omega}_{\mathrm{sl}}$ Slip angular speed $\left(\boldsymbol{\omega}_{\mathrm{s}}-\boldsymbol{\omega}_{\mathrm{r}}\right)$

$T_{e}, T_{1}$ Electromagnetic and load torque

J Moment of inertia

f Friction constant

$\mathbf{T}_{\mathbf{s}}, \mathbf{T}_{\mathbf{r}}$ Stator and rotor time constant

$\mathbf{k}_{\mathrm{vi}}, \mathbf{k}_{\mathrm{vp}}$ Integral and Proportional gain of the IP speed controller

$\mathbf{k}_{\mathrm{ip}}, \mathbf{k}_{\mathrm{ii}}$ Proportional and Integral gain of the PI current controller

$\sigma \sigma$ Total leakage constant

*,^ Reference and Estimated value 